\title{
Evaluations of biomarkers associated with 5-FU sensitivity for non-small-cell lung cancer patients postoperatively
} treated with UFT

\author{
J Nakano', C Huang',', D Liu', D Masuya', T Nakashima', H Yokomise', M Ueno ${ }^{2}$, H Wada $^{3}$ and M Fukushima ${ }^{4}$ \\ 'Faculty of Medicine, Second Department of Surgery, Kagawa University, 1750-1, Miki-cho, Kita-gun, Kagawa 76I-0793, Japan; ${ }^{2}$ Faculty of Medicine, \\ Department of Pathology and Host Defense, Kagawa University, Kagawa, Japan; ${ }^{3}$ Faculty of Medicine, Department of Thoracic Surgery, Kyoto University, \\ 54, Shogoin-kawahara-cho, Sakyo-ku, Kyoto, 606-8397, Japan; ${ }^{4}$ Pathology Optimal Medication Research Laboratory, Taiho Pharmaceutical Co. Ltd, 224- \\ 2. Hiraishi-Ebisuno, Kawauchi-cho, Tokushima-shi, Tokushima 77I-0I32, Japan
}

The sensitivity to 5-fluorouracil (5-FU) has been reported to be associated with target molecule thymidylate synthase (TS), fluoropyrimidine-metabolising enzymes such as orotate phosphoribosyltransferase (OPRT), and dihydropyrimidine dehydrogenase (DPD). We performed an immunohistochemical study on the clinical significance of TS, OPRT, and DPD expression using I5 I resected non-small-cell lung cancer (NSCLC) patients postoperatively treated with a combination of tegafur and uracil (UFT). Eightytwo carcinomas were TS-positive, 105 carcinomas were OPRT-positive, 68 carcinomas were DPD-positive. No correlation was observed in the HSCORE between the TS and OPRT expression $(r=0.203)$, between the TS and DPD expression $(r=0.098)$, or between the OPRT and DPD expression $(r=0.074)$. Regarding the survival of NSCLC patients treated with UFT, the 5-year survival rate of patients with TS-negative tumours was significantly higher than that with TS-positive tumours $(P=0.0$ I 33$)$. The 5 -year survival rate of patients with OPRT-positive stage II to III tumours was significantly higher than that with OPRT-negative stage II to III tumours $(P=0.0145)$. In addition, the 5-year survival rate of patients with DPD-negative tumours was also significantly higher than that with DPD-positive tumours $(P=0.0004)$. A Cox multivariate regression analysis revealed the TS status (hazard ratio 2.663; $P=0.0003$ ), OPRT status (hazard ratio 2.543; $P=0.0005$ ), and DPD status (hazard ratio 2.840; $P<0.000 \mathrm{I}$ ) to all be significant prognostic factors for the survival of resected NSCLC patients postoperatively treated with UFT.

British Journal of Cancer (2006) 95, 607-6I5. doi:I0.1038/sj.bjc.6603297 www.bjcancer.com

Published online I August 2006

(c) 2006 Cancer Research UK

Keywords: lung cancer; 5-FU; thymidylate synthase; orotate phosphoribosyltransferase; dihydropyrimidine dehydrogenase

Lung cancer is one of the most common cancers and the major cause of cancer-related death in North America, Europe, and Japan (Cersosimo, 2002). Non-small-cell lung cancer (NSCLC) comprises about $75 \%$ of all lung cancers. The majority of NSCLC patients have locally advanced stage III or metastatic stage IV disease at diagnosis. In addition, even in the early stage, some NSCLC patients may experience recurrence after surgery. Therefore, new therapeutic strategies are required to improve the clinical outcome of NSCLC patients.

Both experimental and clinical studies based on the molecular biology have revealed many molecules to affect various biological behaviors of malignant tumours including NSCLCs. To improve the treatment of NSCLC patients, it is important to design an optimal therapeutic strategy according to tumour biology (Huang et al, 2005). Therefore, the selection of effective adjuvant therapies based on biomarkers associated with tumour biology, such as made-to-order chemotherapy, is considered to be an effective

*Correspondence: Dr C Huang; E-mail: chuang@kms.ac.jp Received 8 March 2006; revised 26 June 2006; accepted 29 June 2006; published online I August 2006 strategy for NSCLC patients (Rosell et al, 2003; Vokes and Choy, 2003). Thus, the development of highly specific and responsive sensitivity tests for anticancer agents is important to be able to predict the response to an anticancer agent before using it for treatment. Recent experimental and clinical studies have reported several molecular targeted therapies, such as 5-fluorouracil (5-FU)derived agents against thymidylate synthase (TS) (Rustum et al, 1997), Gefitinib or Erlotinib against epidermal growth factor receptor (Mitsudomi et al, 2005), and Bevacizumab against vascular endothelial growth factor-A (Johnson et al, 2004).

Among them, 5-FU-derived agents have been widely used in the treatment of various human cancers, including NSCLCs (Wada et al, 1996; Kato et al, 2004), colorectal cancers (Macdonald and Astrow, 2001), and gastric cancers (Takiuchi and Ajani, 1998), since its introduction into clinical practice more than 40 years ago. Clinical studies have reported their sensitivity to be associated with the target molecule TS (Rustum et al, 1997), fluoropyrimidinemetabolising enzymes such as orotate phosphoribosyltransferase (OPRT) (Peters et al, 1986), and the 5-FU-catabolitic enzyme such as dihydropyrimidine dehydrogenase (DPD) (Beck et al, 1994). However, there were only a few clinical studies on the simultaneous evaluations of these biomarkers to evaluate 5-FU sensitivity (Isshi et al, 2002; Fujii et al, 2003; Ichikawa et al, 2003a). 
Therefore, we performed a clinical study on the clinical significance of TS, OPRT, and DPD expression for the treatment of resected NSCLC patients who were postoperatively treated with oral 5-FU derivatives, UFT (a combination of tegafur and uracil, Taiho Pharmaceutical Co., Tokyo, Japan) (Wada et al, 1996; Kato et al, 2004).

\section{MATERIALS AND METHODS}

\section{Clinical characteristics of patients}

From January 1995 to December 2000, consecutive NSCLC patients who underwent surgery and were postoperatively treated with UFT, at the Second Department of Surgery, Faculty of Medicine, Kagawa University, were studied. This study was approved by the institutional review board of Kagawa University (14-7, a clinical

Table I Patient demographics

\begin{tabular}{|c|c|c|}
\hline Patient characteristics & Number & $\%$ \\
\hline Total number of patients & 151 & 100.0 \\
\hline \multicolumn{3}{|l|}{ Age (years) } \\
\hline Median & 64 & \\
\hline Range & $35-76$ & \\
\hline \multicolumn{3}{|l|}{ Gender } \\
\hline Male & 104 & 68.9 \\
\hline Female & 47 & 31.1 \\
\hline \multicolumn{3}{|l|}{ Smoking habitus } \\
\hline Nonsmoker & 51 & 33.8 \\
\hline Smoker & 100 & 66.2 \\
\hline \multicolumn{3}{|l|}{ ECOG performance status } \\
\hline 0 & 85 & 56.3 \\
\hline I & 57 & 37.7 \\
\hline 2 & 9 & 6.0 \\
\hline \multicolumn{3}{|l|}{ Pathological stage } \\
\hline I & 62 & 41.1 \\
\hline ॥ & 28 & 18.5 \\
\hline III & 61 & 40.4 \\
\hline \multicolumn{3}{|l|}{ Differentiation } \\
\hline Well & 46 & 30.5 \\
\hline Moderately & 54 & 35.7 \\
\hline Poorly & 51 & 33.8 \\
\hline \multicolumn{3}{|l|}{ Histology } \\
\hline Adenocarcinoma & 84 & 55.6 \\
\hline Squamous cell carcinoma & 56 & 37.1 \\
\hline Large cell carcinoma & 11 & 7.3 \\
\hline \multicolumn{3}{|l|}{ Method of surgical resection } \\
\hline Pneumonectomy & 14 & 9.3 \\
\hline Lobectomy & 123 & 81.5 \\
\hline Segmentectomy & 4 & 2.6 \\
\hline Wedge resection & 10 & 6.6 \\
\hline \multicolumn{3}{|l|}{ Chemothrapy } \\
\hline Platinum-based chemotherapy & 79 & 52.3 \\
\hline Neoadjuvant MVP & 30 & 19.8 \\
\hline Neoadjuvant CBDCA/PTX & 9 & 6.0 \\
\hline Postoperative adjuvant MVP & 26 & 17.2 \\
\hline Postoperative adjuvant CBDCA/PTX & 14 & 9.3 \\
\hline UFT & $|5|$ & 100.0 \\
\hline Radiotherapy & 24 & 15.9 \\
\hline
\end{tabular}

CBDCA/PTX = carboplatin/paclitaxel; ECOG = Eastern Cooperative Oncology Group; MVP = mitomycin/vinblastin/cisplatin; UFT = a combination of tegafur and uracil. study of biological markers in NSCLCs) and signed informed consent was obtained from each patient. Tumour node metastasis staging designations were made according to the postsurgical pathological international staging system (Mountain, 1997). In total, 151 patients with lung cancer up to stage III were investigated (Table 1). They included 62 patients with stage I NSCLCs, 28 patients with stage II NSCLCs, and 61 patients with stage III NSCLCs. The patients' clinical records and histopathological diagnoses were fully documented. This report includes follow-up data as of 31 October 2005. The median follow-up period for all patients was 65.7 months.

Regarding the methods for a surgical resection, a pneumonectomy was performed in 14 patients with stage II to III NSCLCs. A lobectomy was performed in 123 patients; in 48 patients with stage I NSCLCs, in 26 patients with stage II NSCLCs, and in 49 patients with stage III NSCLCs. A segmentectomy was performed in four patients with stage I NSCLCs, and a wedge resection was performed in 10 patients with stage I NSCLCs. Platinum-based chemotherapy using mitomycin/vinblastin/cisplatin or carboplatin/ paclitaxel was performed in 79 patients with stage II to III NSCLCs; neoadjuvant chemotherapy in 39 patients, and postoperative adjuvant chemotherapy in 40 patients with nodal metastases. Radiation therapy was performed in 24 patients; in 17 patients with $\mathrm{T} 3$ or $\mathrm{T} 4$ status and in seven patients with mediastinal lymph node metastases. The oral administration of UFT (300-400 mg day ${ }^{-1}$ body $\left.^{-1}\right)$ was started within 1 month after surgery. UFT was administered for 2 years if there was no recurrence of carcinomas. In patients with recurrences, UFT was given until its oral administration became impossible.

\section{Immunohistochemistry}

Formalin-fixed paraffin-embedded tissue was cut into $4-\mu \mathrm{m}$ sections and mounted on poly-L-lysine-coated slides. The sections were deparaffinised and rehydrated. The slides were then heated in a microwave for $10 \mathrm{~min}$ in a $10-\mu \mathrm{moll}^{-1}$ citrate buffer solution at $\mathrm{pH} 6.0$, and cooled to room temperature for $20 \mathrm{~min}$. After quenching the endogenous peroxidase activity with $0.3 \% \mathrm{H} 2 \mathrm{O} 2$ (in absolute methanol) for $30 \mathrm{~min}$, the sections were treated for $2 \mathrm{~h}$ at room temperature with $5 \%$ bovine serum albumin to block nonspecific staining. Duplicate sections were incubated overnight with the primary specific antibodies detecting TS (rabbit IgG, diluted at $1: 500$ ), OPRT (rabbit IgG, diluted at $1: 1000$ ), and DPD (rabbit IgG, diluted at 1:500) (Huang et al, 2000). The slides were then incubated for $1 \mathrm{~h}$ with biotinylated anti-rabbit IgG (Vector Laboratories Inc., Burlingame, CA, USA). The sections were incubated with the avidin-biotin-peroxidase complex (Vector Laboratories Inc.) for $1 \mathrm{~h}$, and antibody binding was visualised with 3,3'-diaminobenzidine tetrahydrochloride. Finally, the sections were lightly counterstained with Mayer's hematoxylin. The human colon cancer cell line DLD-1/FrUrd was used as a positive control for the staining of TS. Sections of resected lung tumours to express OPRT were used as positive controls for the staining of OPRT. The human pancreatic cancer cell line MIAPaCa-2 was used as a positive control for the staining of DPD. A rabbit IgG was used as a negative control during each run of immunohistochemical staining.

All of the immunostained sections were reviewed by two authors (J Nakano and M Ueno) who had no knowledge of the patients' clinical status. In cases of multiple areas of low intensity, five areas selected at random were scored. In sections where all of the staining appeared to be intense, one random field was selected. At least 200 tumour cells were scored per $\times 40$ field. All sections were scored in a semiquantitative manner according to a previously described method, which reflects both the intensity and percentage of cells staining at each intensity (McCarty et al, 1986). Intensity was classified as 0 (no staining), +1 (weak staining), +2 (distinct staining), or +3 (very strong staining). A value designated as the 'HSCORE' was obtained for each slide by using the following 
algorithm: HSCORE $=\sum(I \times \mathrm{PC})$, where $I$ and PC represent the staining intensity and the percentage of cells that stain at each intensity, respectively. And the corresponding HSCOREs were calculated separately. Concerning TS expression, when the HSCORE of TS in a given specimen was $\geqslant 30$, the sample was classified as TS-positive, the same as reported previously (Huang et al, 2000). Concerning OPRT expression, the sample was classified as OPRT-positive when the HSCORE of OPRT in a given specimen was $\geqslant 30$, because the cutoff line of 30 showed the most significant association with a survival difference. Concerning DPD expression, when the HSCORE of DPD in a given specimen was $\geqslant 50$, the sample was classified as DPD-positive, the same as reported previously (Huang et al, 2000).

\section{Statistical analysis}

The statistical differences in the expression of each biological marker in relation to various clinical and pathological parameters were assessed by the $\chi^{2}$-test. Overall survival was defined as the time from treatment initiation (surgical resection, chemotherapy, or radiation) to the date of death from any cause. The KaplanMeier method was used to estimate the probability of overall survival as a function of time, and differences in the survival of subgroups of patients were compared by using Mantel's log-rank test. A multivariate analysis was performed using the Cox regression model to study the effects on survival (Cox, 1972). All $P$-values were based on two-tailed statistical analysis, and a $P$-value $<0.05$ was considered to indicate statistical significance.

\section{RESULTS}

\section{Clinical significance of intratumoural TS expression in NSCLCs treated with UFT}

The intratumoural TS expression appeared in a cytoplasmic staining pattern (Figure 1A and 1B). Of the 151 NSCLCs we studied, 82 carcinomas $(54.3 \%)$ were TS-positive, and 69 carcinomas $(45.7 \%)$ were TS-negative (Table 2). The frequency of TS-positive tumours was significantly higher in squamous cell carcinomas than in adenocarcinomas (69.6 vs $42.9 \%, P=0.0063)$. However, there was no difference in the TS status according to tumour status, nodal status, pathological stage, tumour differentiation, or neoadjuvant chemotherapy.

Regarding the survival of NSCLC patients treated with UFT, the 5 -year survival rate of patients with TS-negative tumours was significantly higher than that with TS-positive tumours (69.1 vs $44.7 \%, P=0.0133$, Figure 2A). Regarding the pathological stage, the 5-year survival rate of patients with TS-negative stage I tumours was significantly higher than that with TS-positive stage I tumours (86.2 vs 63.2\%, $P=0.0426$, Figure $2 \mathrm{~B})$. In addition, the 5year survival rate of patients with TS-negative stage II to III tumours was also significantly higher than that with TS-positive stage II to III tumours (55.6 vs $27.9 \%, P=0.0259$, Figure $2 \mathrm{C}$ ).

\section{Clinical significance of intratumoural OPRT expression in NSCLCs treated with UFT}

The intratumoural OPRT expression appeared in a cytoplasmic staining pattern (Figure 1C and D). Of the 151 NSCLCs, 105 carcinomas (69.5\%) were OPRT-positive, and 46 carcinomas $(30.5 \%)$ were OPRT-negative (Table 2). There was no difference in the OPRT status according to tumour histology, tumour status, nodal status, pathological stage, tumour differentiation, or neoadjuvant chemotherapy.

Regarding the survival of NSCLC patients treated with UFT, there was no significant difference in the 5-year survival rates between patients with OPRT-positive tumours and patients with OPRT-negative tumours (60.6 vs $48.0 \%$, Figure $3 \mathrm{~A}$ ). Regarding the pathological stage, there was also no significant difference in the 5 -year survival rates of patients with stage I NSCLCs, according to the OPRT status (Figure 3B). However, among locally advanced stage II to III, the 5-year survival rate of patients with OPRTpositive tumours was significantly higher than that with OPRTnegative tumours (50.8 vs $25.0 \%, P=0.0145$, Figure $3 C$ ).

\section{Clinical significance of intratumoural DPD expression in NSCLCs treated with UFT}

The intratumoural DPD expression appeared in a cytoplasmic staining pattern (Figure $1 \mathrm{E}$ and $1 \mathrm{~F}$ ). Of the 151 NSCLCs, 68 carcinomas (45.0\%) were DPD-positive, and 83 carcinomas $(55.0 \%)$ were DPD-negative (Table 2$)$. There was no difference in the DPD status according to tumour histology, tumour status, nodal status, pathological stage, tumour differentiation, or neoadjuvant chemotherapy.

Regarding the survival of NSCLC patients treated with UFT, the 5 -year survival rate of patients with DPD-negative tumours was significantly higher than that with DPD-positive tumours (66.6 vs $42.6 \%, P=0.0004$, Figure $4 \mathrm{~A}$ ). Regarding the pathological stage, the 5-year survival rate of patients with DPD-negative stage I tumours was significantly higher than that with DPD-positive stage I tumours (79.8 vs $63.0 \%, P=0.0391$, Figure 4B). In addition, the 5 -year survival rate of patients with DPD-negative stage II to III tumours was also significantly higher than that with DPD-positive stage II to III tumours (52.4 vs $31.0 \%, P=0.0174$, Figure $4 \mathrm{C}$ ).

\section{Prognostic factors of resected NSCLC patients treated with UFT}

No correlation was observed in the HSCORE between the TS expression and OPRT expression $(r=0.203)$, between the TS expression and DPD expression $(r=0.098)$, or between the OPRT expression and DPD expression $(r=0.074)$. A Cox multivariate regression analysis of the prognostic variables for resected NSCLC patients treated with UFT is shown in Table 3. Five variables, including the TS status (hazard ratio 2.663; $P=0.0003$ ), OPRT status (hazard ratio 2.534; $P=0.0005$ ), DPD status (hazard ratio $2.840 ; P<0.0001$ ), pathological stage (hazard ratio 1.908; $P<0.0001$ ), and the methods of surgical resection (a pneumonectomy $v s$ other methods)(hazard ratio 2.555; $P=0.0242$ ), were demonstrated to be significant prognostic factors for survival of resected NSCLC patients postoperatively treated with UFT.

\section{DISCUSSION}

5-Fluorouracil is one of the most widely used antitumour chemothrapeutic agents for the treatment of a variety of human malignancies, especially in terms of the patient quality of life and economy (Wada et al, 1996). In fact, prospective randomised clinical studies have found the administration of UFT to be an effective adjuvant chemotherapy for NSCLC patients (Wada et al, 1996; Kato et al, 2004). On the other hand, many experimental and clinical studies have also revealed the 5-FU sensitivity to be affected by several biomarkers, such as its target molecule TS (Rustum et al, 1997), several fluoropyrimidine metabolising enzymes (Peters et al, 1986; Peters et al, 1991), and DPD, an enzyme of 5-FU catabolism (Beck et al, 1994).

First of all, regarding TS, its activity is necessary for cell proliferation because it catalyses the conversion of deoxyuridine$5^{\prime}$-monophosphate to deoxythymidine- $5^{\prime}$-monophosphate, an essential step in DNA synthesis. After 5-FU is converted into 5fluoro- $2^{\prime}$-deoxyuridine $5^{\prime}$-monophosphate (FdUMP), this activated molecule forms a tight-binding complex with TS and 5,10methylene-tetrahydrofolate, thus resulting in the inhibition of the TS activity (Rustum et al, 1997). Thymidylate synthase is 

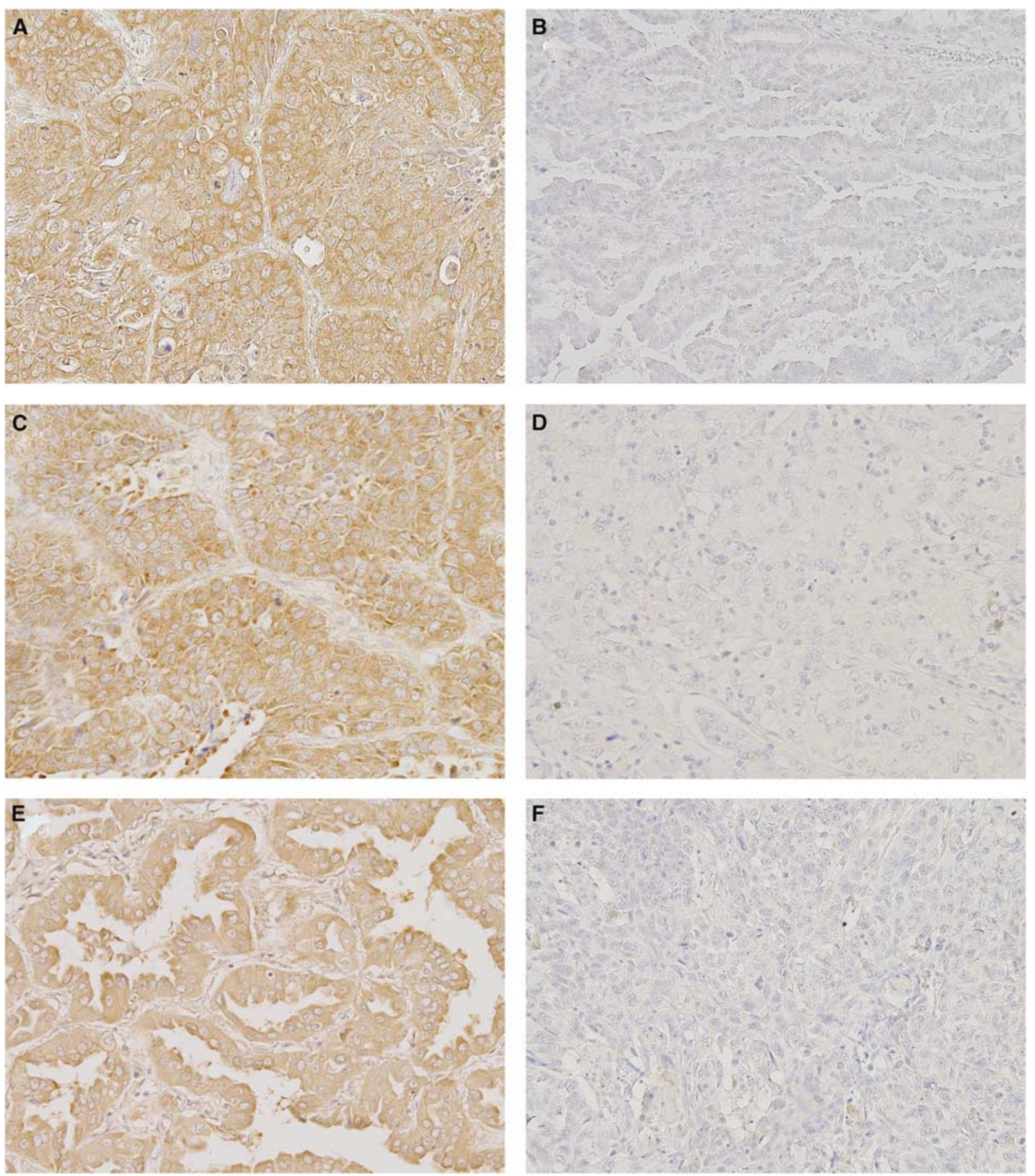

Figure I Immunohistochemical staining of human NSCLC tissues (original magnification, $\times 100)$. (A. B) Carcinoma with positive and negative TS expression, (C, D) carcinoma with positive and negative OPRT expression,

therefore a target molecule of 5-FU. In addition, previous studies have reported that the regulation of the TS expression was affected by several mechanisms, including the polymorphism of the tandem repeated sequences in the promoter enhancer region of its gene and the genetic amplification of 18p (Horie et al, 1995; Hidaka et al, 2003).

In fact, many previous studies have reported the intratumoural TS expression to be associated with tumour proliferation (Navalgund et al, 1980; Nakagawa et al, 2004), the responsiveness to 5-FU (Johnston et al, 1995; Yeh et al, 1998). In addition, the overexpression of TS is reported to be associated with a poor prognosis of many cancer patients treated with 5-FU, including NSCLCs
(Huang et al, 2000) and gastrointestinal cancers (Lenz et al, 1996). The present study in a relatively large number of patients treated with UFT also revealed that the survival of patients with TS-negative tumours was significantly better than that with TS-positive tumours. Furthermore, the significant differences in the survival of patients were observed in stage I cases as well as in locally advanced stage II to III cases. These results might be due to not only the responsiveness to 5-FU but also tumour proliferation (Nakagawa et al, 2004; Huang et al, 2005). In fact, recent studies have found that TS exhibits an oncogene-like activity (Rahman et al, 2004). In addition, the overexpression of TS itself is an independent factor for a poor prognosis in NSCLC patients (Huang et al, 2005). 
Table 2 Distribution of biomarkers in I5I NSCLC patients according to clinicopathological characteristics

\begin{tabular}{|c|c|c|c|c|c|c|c|}
\hline \multirow[b]{2}{*}{ Characteristics } & \multirow[b]{2}{*}{$n$} & \multicolumn{2}{|c|}{ TS-positive } & \multicolumn{2}{|c|}{ OPRT-positive } & \multicolumn{2}{|c|}{ DPD-positive } \\
\hline & & (\%) & $P$-value & (\%) & $P$-value & (\%) & $P$-value \\
\hline \multicolumn{8}{|l|}{ Smoking } \\
\hline $\begin{array}{l}\text { Nonsmoker } \\
\text { Smoker }\end{array}$ & $\begin{array}{r}51 \\
100\end{array}$ & $\begin{array}{l}52.0 \\
58.8\end{array}$ & 0.4260 & $\begin{array}{l}70.6 \\
69.0\end{array}$ & 0.8411 & $\begin{array}{l}54.9 \\
40.0\end{array}$ & 0.1167 \\
\hline \multicolumn{8}{|l|}{ Tumour status } \\
\hline $\begin{array}{l}\text { TI, T2 } \\
\text { T3, T4 }\end{array}$ & $\begin{array}{r}102 \\
49\end{array}$ & $\begin{array}{l}56.9 \\
49.0\end{array}$ & 0.3626 & $\begin{array}{l}73.5 \\
61.2\end{array}$ & 0.1240 & $\begin{array}{l}40.2 \\
55.1\end{array}$ & 0.1211 \\
\hline \multicolumn{8}{|l|}{ Nodal status } \\
\hline $\begin{array}{l}\text { No } \\
\text { NI, N2 }\end{array}$ & $\begin{array}{l}88 \\
63\end{array}$ & $\begin{array}{l}48.9 \\
61.9\end{array}$ & 0.1127 & $\begin{array}{l}67.0 \\
73.0\end{array}$ & 0.4319 & $\begin{array}{l}38.6 \\
54.0\end{array}$ & 0.0887 \\
\hline \multicolumn{8}{|l|}{ Pathological stage } \\
\hline $\begin{array}{l}\text { Stage I } \\
\text { Stage II } \\
\text { Stage III }\end{array}$ & $\begin{array}{l}62 \\
28 \\
61\end{array}$ & $\begin{array}{l}53.2 \\
50.0 \\
57.4\end{array}$ & 0.7905 & $\begin{array}{l}66.1 \\
78.6 \\
68.9\end{array}$ & 0.4886 & $\begin{array}{l}35.5 \\
42.9 \\
55.7\end{array}$ & 0.0757 \\
\hline \multicolumn{8}{|l|}{ Differentiation } \\
\hline $\begin{array}{l}\text { Well } \\
\text { Moderately } \\
\text { Poorly }\end{array}$ & $\begin{array}{l}46 \\
54 \\
51\end{array}$ & $\begin{array}{l}60.9 \\
44.4 \\
58.8\end{array}$ & 0.1888 & $\begin{array}{l}65.2 \\
75.9 \\
66.7\end{array}$ & 0.4395 & $\begin{array}{l}43.5 \\
44.4 \\
47.1\end{array}$ & 0.9338 \\
\hline \multicolumn{8}{|l|}{ Histology } \\
\hline $\begin{array}{l}\text { Adenocarcinoma } \\
\text { Squamous cell } \\
\text { carcinoma }\end{array}$ & $\begin{array}{l}84 \\
56\end{array}$ & $\begin{array}{l}42.9 \\
69.6\end{array}$ & 0.0063 & $\begin{array}{l}69.0 \\
76.8\end{array}$ & 0.3170 & $\begin{array}{l}47.6 \\
39.3\end{array}$ & 0.5025 \\
\hline $\begin{array}{l}\text { Large cell } \\
\text { carcinoma } \\
\text { Neoadjuvant } \\
\text { chemotherapy }\end{array}$ & 11 & 63.6 & & 36.4 & & 54.5 & \\
\hline $\begin{array}{l}\text { Neoadjuvant } \\
\text { MVP }\end{array}$ & 30 & 60.0 & 0.3700 & 53.3 & 0.0943 & 50.0 & 0.6691 \\
\hline $\begin{array}{l}\text { Neoadjuvant } \\
\text { CBDCA/PTX }\end{array}$ & 9 & 33.3 & & 77.8 & & 33.3 & \\
\hline $\begin{array}{l}\text { Without } \\
\text { neoadjuvant }\end{array}$ & 112 & 54.5 & & 73.2 & & 44.6 & \\
\hline Total number of patients & $|5|$ & 54.3 & & 69.5 & & 45.0 & \\
\hline
\end{tabular}

CBDCA/PTX = carboplatin/paclitaxel; MVP = mitomycin/vinblastin/cisplatin; NSCLC $=$ non-small-cell lung cancer.

Secondly, because 5-FU itself is a prodrug which requires its intracellular conversion, interindividual variation in the activity of fluoropyrimidine-metabolising enzymes can affect the activation of 5-FU. In general, phosphorylation is necessary to activate 5-FU by one or more of three pathways (Peters et al, 1986; Peters et al, 1991). Among them, OPRT is considered to be a major enzyme in the 5-FU conversion, directly to 5-fluorouridine $5^{\prime}$-monophosphate (FUMP) leading to the formation of FdUMP in the presence of 5phosphoribosyl-1-pyrophosphate as a cofactor (Shirasaka et al, 1993). Experimental studies using cell lines have revealed a decreased expression and activity of OPRT to be associated with resistance to 5-FU (Chung et al, 2000; Murakami et al, 2000). Although the true mechanisms for the downregulation of OPRT expression in human cancers are still unclear, an experimental study has suggested the loss of $3 q$ to be a genetic change responsible for the decreased OPRT activity and acquired resistance to 5-FU (Hidaka et al, 2003). Furthermore, the adenoviral-mediated transduction of OPRT gene was reported to result in a marked sensitisation of tumour cells to 5-FU cytotoxicity (Kanai et al, 1998).

Previous clinical studies also revealed the positive expression and activity of OPRT to be associated with the responsiveness to 5 -FU in a variety of human cancers, including colorectal cancers

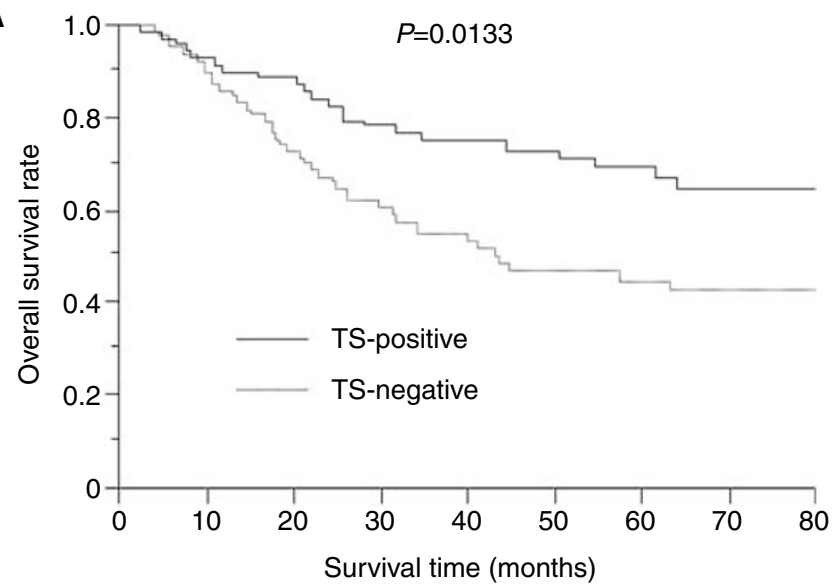

B

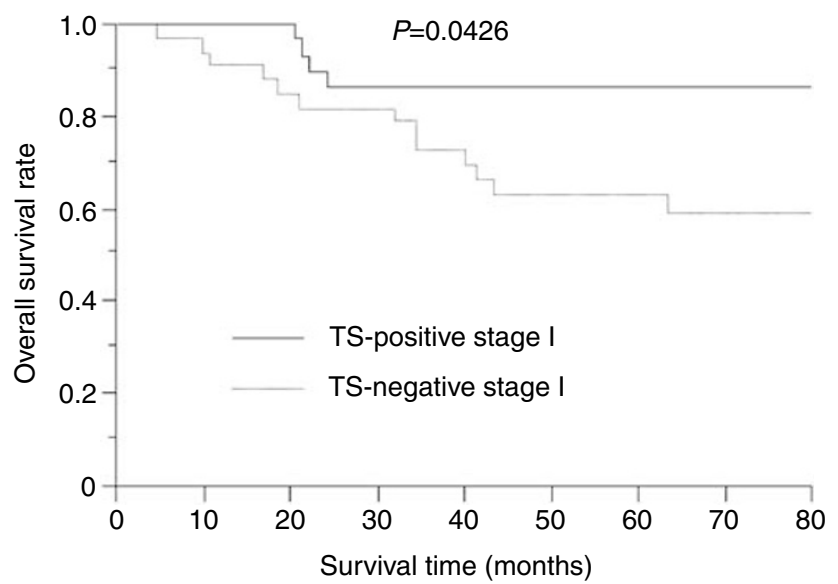

C

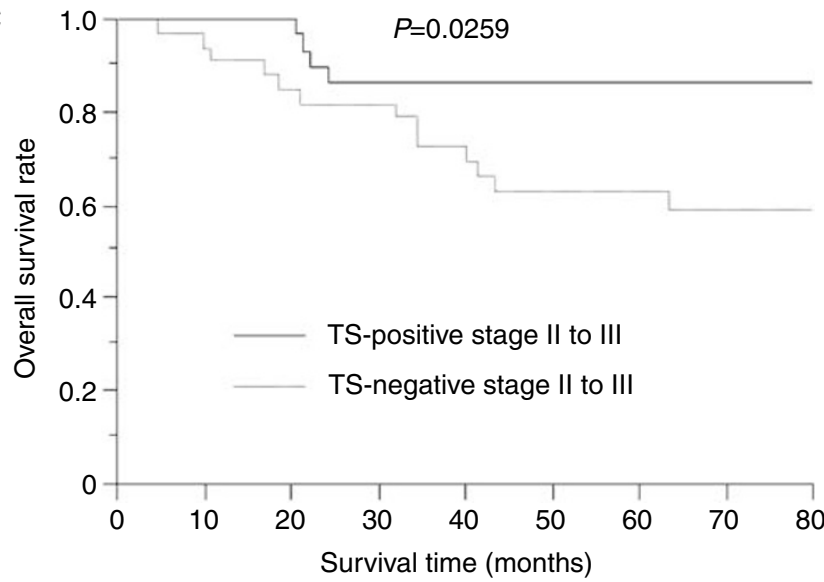

Figure 2 Overall survival of NSCLC patients treated UFT in relation to TS status. (A) Total NSCLCs. (B) Stage I NSCLCs. (C) Stage II to III NSCLC.

(Isshi et al, 2002; Fujii et al, 2003; Ichikawa et al, 2003a; Matsuyama et al, 2006) and bladder carcinomas (Mizutani et al, 2004). However, these studies were performed using relatively small number of patients, and then were evaluated by biochemical assays for OPRT enzyme activity or reverse transcriptional PCR (RT - PCR) assays for OPRT gene expression. Biochemical assays are difficult to perform in clinical use, and they need a large volume of sample tissue. In the present study, we evaluated the intratumoural OPRT expression by immunohistochemistry using an anti-OPRT polyclonal antibody, obtained by immunising rabbits with the OPRT peptide. The immunochemical detection 

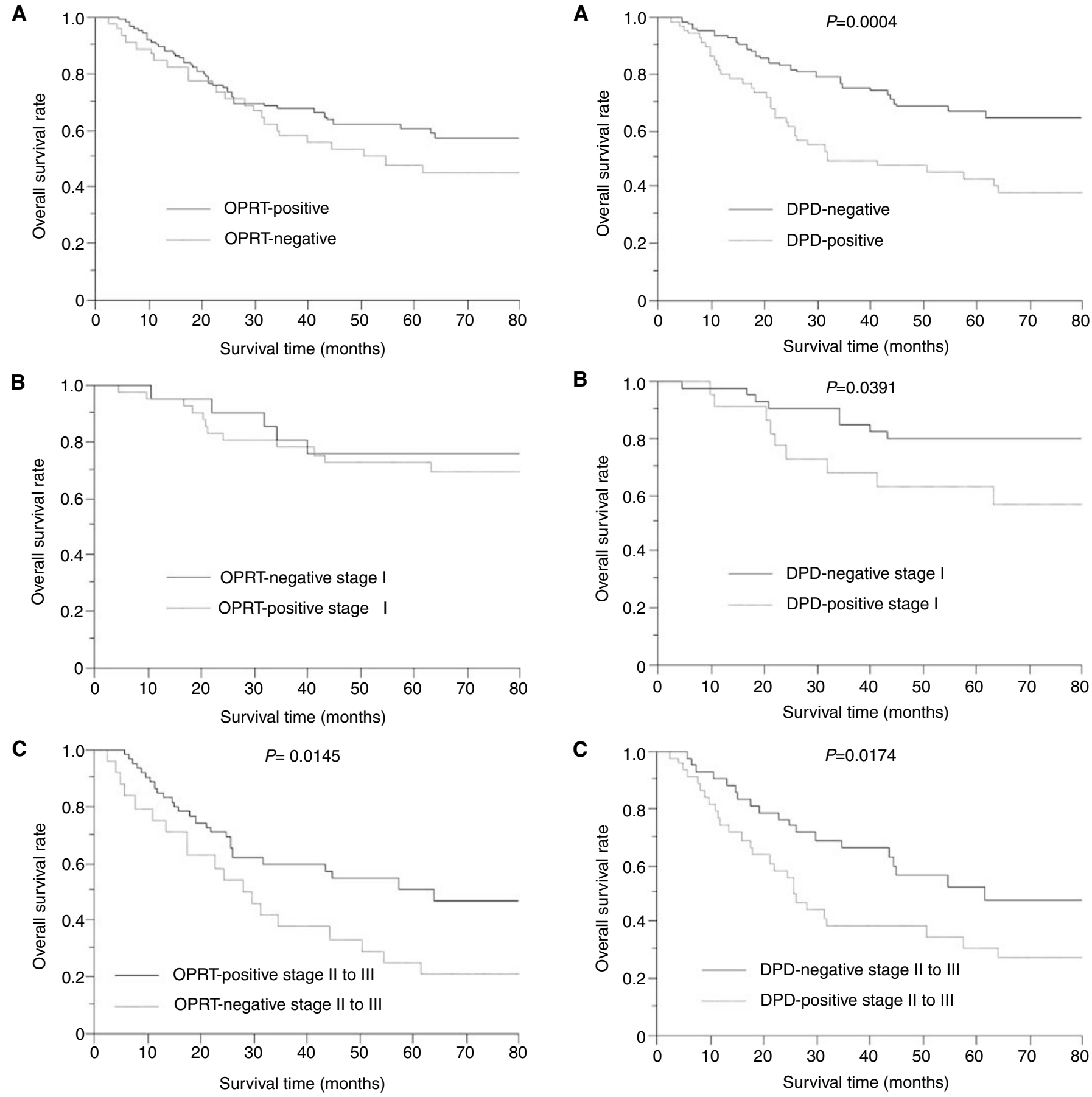

Figure 3 Overall survival of NSCLC patients treated UFT in relation to OPRT status. (A) Total NSCLCs. (B) Stage I NSCLCs. (C) Stage II to III NSCLC.

using this antibody was found to positively correlate with the OPRT enzyme activity (Sakamoto et al, 2005), and immunohistochemical assays are easy to perform in clinical use. Consequently, the present study demonstrated the positive expression of OPRT to be one of the significant factors for a good survival for resected NSCLC patients postoperatively treated with UFT, especially in advanced stage II to III. To our knowledge, the present study was the first clinical report using immunohistochemistry, to demonstrate the clinical significance of the OPRT expression in a relatively large number of cancer patients treated with UFT. In fact, a recent clinical study also revealed a positive OPRT activity to be

Figure 4 Overall survival of NSCLC patients treated UFT in relation to DPD status. (A) Total NSCLCs. (B) Stage I NSCLCs. (C) Stage II to III NSCLC.

associated with a better prognosis in resectable colorectal cancer patients treated with oral 5-FU (Ochiai et al, 2006).

On the other hand, regarding other pathways of 5-FU activation, thymidine phosphatase (TP) is considered to not be important because of the lack of its cofactor dRib-1-P at physiological concentrations (Barankiewicz and Henderson, 1977). Conversely, high $\mathrm{TP}$ concentration in conjunction with the normally low dRib-1-P drive the reaction in the opposite direction (Ackland and Peters, 1999). In fact, no difference was observed in the survivals of NSCLC patients treated with UFT according to the intratumoural TP expression in our pilot study by immunohistochemistry (data not shown). 
Table 3 Multivariate regression analysis in predicting survival of NSCLC patients treated with UFT

\begin{tabular}{|c|c|c|c|c|}
\hline Variables & Assigned score & Hazard ratio & $95 \% \mathrm{Cl}$ & $P$-value \\
\hline \multicolumn{5}{|l|}{ TS status } \\
\hline Negative & 0 & 2.663 & $1.567-4.526$ & 0.0003 \\
\hline Positive & 1 & & & \\
\hline \multicolumn{5}{|l|}{ OPRT status } \\
\hline Positive & 0 & 2.543 & $1.508-4.287$ & 0.0005 \\
\hline Negative & I & & & \\
\hline \multicolumn{5}{|l|}{ DPD status } \\
\hline Negative & 0 & 2.840 & $1.685-4.786$ & $<0.000$ \\
\hline Positive & 1 & & & \\
\hline \multicolumn{5}{|c|}{ ECOG performance status } \\
\hline 0 & 0 & $1.30 \mid$ & $0.825-2.051$ & 0.25 \\
\hline I & 1 & & & \\
\hline 2 & 2 & & & \\
\hline \multicolumn{5}{|l|}{ Pathological stage } \\
\hline I & 1 & 1.908 & $1.406-2.588$ & $<0.00$ \\
\hline$\|$ & 2 & & & \\
\hline III & 3 & & & \\
\hline \multicolumn{5}{|l|}{ Differentiation } \\
\hline Well & 0 & 1.296 & $0.949-1.769$ & 0.102 \\
\hline Moderately & 1 & & & \\
\hline Poorly & 2 & & & \\
\hline \multicolumn{5}{|c|}{ Method of surgical resection } \\
\hline Other methods & 0 & 2.555 & I. I $30-5.776$ & 0.02 \\
\hline Pneumonectomy & 1 & & & \\
\hline
\end{tabular}

$\mathrm{Cl}=$ confidence interval; $\mathrm{DPD}=$ dihydropyrimidine dehydrogenase; $\mathrm{NSCLC}=$ nonsmall-cell lung cancer; OPRT = orotate phosphoribosyltransferase; TS = thymidylate synthase; UFT = a combination of tegafur and uracil.

Third, due to the fact that $80-90 \%$ of the administered $5-\mathrm{FU}$ is degraded by DPD in humans, the first and rate-limiting enzyme of 5-FU catabolism, only a small part of the 5-FU is activated (Fischel et al, 1995). As a result, 5-FU degradation generally occurs in all tissues, including tumour tissues, but it reaches its highest level in the liver (Ho et al, 1986). In fact, a congenital deficiency of DPD can result in severe life-threatening toxicity when $5-\mathrm{FU}$ is administered (Wei et al, 1996). In contrast, many experimental studies have demonstrated the intratumoural DPD activity to affect the resistance to 5-FU (Beck et al, 1994; Ishikawa et al, 1999). Previous clinical studies also found an overexpression of DPD in tumour cells to be associated with 5-FU resistance (Higashiyama et al, 2001) and a poor prognosis in many cancer patients treated with 5-FU, including NSCLCs (Huang et al, 2000; Nakagawa et al, 2002), colorectal cancers (Ichikawa et al, 2003b), and breast cancers (Horiguchi et al, 2004). Although several clinical studies reported DPD expression to not be associated with the survival of cancer patients treated with 5-FU (Ikeguchi et al, 2002; Kornmann et al, 2002; Hakamada et al, 2005), this discrepancy might be due to the different types of 5-FU administration such as intravenous infusion, the different antibody used, or the contamination of intratumoural stromal cells.

\section{REFERENCES}

Ackland SP, Peters GJ (1999) Thymidine phosphorylase: its role in sensitivity and resistance to anticancer drugs. Drug Resist Updat 2: $205-214$

Barankiewicz J, Henderson JF (1977) Ribose 1-phosphate metabolism in Ehrlich ascites tumor cells in vitro. Biochim Biophys Acta 479: $371-377$
Based on these facts about the biomarkers associated with sensitivity to 5-FU, we thus considered a clinical study to simultaneously evaluate the expressions of TS, OPRT, and DPD, to be important for establishing the protocol of made-to-order chemotherapy for NSCLC patients. Therefore, we performed the present study using a relatively large number of patients treated with UFT. Consequently, the intratumoural expressions of TS, OPRT, and DPD were found to be independent of each other. Furthermore, a Cox multivariate analysis demonstrated all the intratumoural expressions of TS, OPRT, and DPD to be independent prognostic factors for resected NSCLC patients postoperatively treated with UFT. As a result, regarding the biomarkers associated with sensitivity to 5-FU, the survival of patients with TS-negative, OPRT-positive, and DPD-negative NSCLCs, which appeared in $12.6 \%$ (19 of 151) in the present study, was the highest among resected NSCLC patients treated with UFT.

Besides these biomarkers associated with sensitivity to 5-FU, the present study revealed that pathological stage and methods of surgical resection (a pneumonectomy vs other methods) were also independent prognostic factors for the resected NSCLC patients treated with UFT. Previous clinical studies also demonstrated that the survival of patients treated with a pneumonectomy is worse than that of patients treated with other surgical methods (Rocco et al, 1996; Ludwig et al 2005). On the other hand, regarding chemotherapy, most of patients with locally advanced stage II to III NSCLCs were treated with either neoadjuvant or postoperative adjuvant platinum-based chemotherapy using mitomycin/vinblastin/cisplatin or carboplatin/paclitaxel in the present study. However, we found no difference in the survivals of patients according to the platinum-based chemotherapy (data not shown). In order to clarify the clinical significance of the platinum-based chemotherapy for NSCLC patients, a randomised prospective study should thus be performed. Furthermore, among the locally advanced stage II to III cases, no difference was observed in the survivals of patients according to radiotherapy in the present study (data not shown). In fact, previous clinical studies also reported that radiotherapy itself has less survival benefit for NSCLC patients (Dautzenberg et al, 1999).

The efficacy of UFT is still lower in NSCLCs than in gastrointestinal cancers. For one reason, NSCLCs are human tumours with a high expression of DPD because DPD-positive tumours occurred in $45 \%$ of NSCLCs in the present study. Therefore, it is important to inhibit the DPD activity to improve the responsiveness to 5-FU against DPD-positive NSCLCs. Recently, S-1 (a combination of tegafur, gimeracil, and oteracil potassium, Taiho) has been developed for clinical use (Chu et al, 2004; Ichinose et al, 2004). Gimeracil used in S-1 is a stronger inhibitor for the intratumoural DPD activity than uracil used in UFT. As a result, S-1 might be more effective for patients with TS-negative, OPRT-positive, and DPD-positive NSCLCs, which occurred in $15.9 \%$ (24 of 151 ) in the present study. Therefore, patients with TS-negative and OPRT-positive NSCLCs, which appeared in $28.5 \%$ (43 of 151 ) in the present study, could be successfully treated by S-1 without evaluating the intratumoural DPD activity. In order to develop and simplify the protocol of made-to-order chemotherapy, a further randomised prospective study using S-1 should thus be performed to evaluate this possibility.

Beck A, Etienne MC, Cheradame S, Fischel JL, Formento P, Renee N, Milano G (1994) A role for dihydropyrimidine dehydrogenase and thymidylate synthase in tumour sensitivity to fluorouracil. Eur J Cancer 30A: 1517-1522 Cersosimo RJ (2002) Lung cancer: a review. Am J Health Syst Pharm 59: $611-642$ 
Chu QS, Hammond LA, Schwartz G, Ochoa L, Rha SY, Denis L, Molpus K, Roedig B, Letrent SP, Damle B, DeCillis AP, Rowinsky EK (2004) Phase I and pharmacokinetic study of the oral fluoropyrimidine S-1 on a oncedaily-for-28-day schedule in patients with advanced malignancies. Clin Cancer Res 10: $4913-4921$

Chung YM, Park S, Park JK, Kim Y, Kang Y, Yoo YD (2000) Establishment and characterization of 5-fluorouracil-resistant gastric cancer cells. Cancer Lett 159: 95-101

Cox DR (1972) Regression models and life-tables. J R Stat Soc B 34: 187 202

Dautzenberg B, Arriagada R, Chammard AB, Jarema A, Mezzetti M, Mattson K, Lagrange J, Pechoux C, Lebeau B, Chastang C (1999) A controlled study of postoperative radiotherapy for patients with completely resected nonsmall cell lung carcinoma. Cancer 86: 265-273

Fischel JL, Etienne MC, Spector T, Formento P, Renee N, Milano G (1995) Dihydropyrimidine dehydrogenase: a tumoral target for fluorouracil modulation. Clin Cancer Res 1: 991-996

Fujii R, Seshimo A, Kameoka S (2003) Relationships between the expression of thymidylate synthase, dihydropyrimidine dehydrogenase, and orotate phosphoribosyltransferase and cell proliferative activity and 5-fluorouracil sensitivity in colorectal carcinoma. Int J Clin Oncol 8: $72-78$

Hakamada Y, Tsuchida A, Arima M, Kubouchi T, Tokita H, Ota D, Kaise H, Aoki T, Kusama M, Aoki T (2005) Prognostic predictors in breast cancer patients with postoperative 5-fluorouracil-based chemotherapy. Int J Mol Med 16: 309-314

Hidaka S, Yasutake T, Fukushima M, Yano H, Haseba M, Tsuji T, Sawai T, Yamaguchi H, Nakagoe T, Ayabe H, Tagawa Y (2003) Chromosomal imbalances associated with acquired resistance to fluoropyrimidines in human colorectal cancer cells. Eur J Cancer 39: 975-980

Higashiyama M, Kodama K, Yokouchi H, Takami K, Fukushima M, Minamigawa K, Takano T, Kobayashi H (2001) Thymidylate synthase and dihydropyrimidine dehydrogenase activities in non-small cell lung cancer tissues: relationship with in vitro sensitivity to 5-fluorouracil. Lung Cancer 34: 407-416

Ho DH, Townsend L, Luna MA, Bodey GP (1986) Distribution and inhibition of dihydrouracil dehydrogenase activities in human tissues using 5-fluorouracil as a substrate. Anticancer Res 6: 781-784

Horie N, Aiba H, Oguro K, Hojo H, Takeishi K (1995) Functional analysis and DNA polymorphism of the tandemly repeated sequences in the $5^{\prime}$ terminal regulatory region of the human gene for thymidylate synthase. Cell Struct Funct 20: $191-197$

Horiguchi J, Yoshida T, Koibuchi Y, Iijima K, Ninomiya J, Takei H, Yokoe T, Ino Y, Morishita Y (2004) DPD activity and immunohistochemical DPD expression in human breast cancer. Oncol Rep 11: 65-72

Huang CL, Yokomise H, Kobayashi S, Fukushima M, Hitomi S, Wada H (2000) Intratumoral expression of thymidylate synthase and dihydropyrimidine dehydrogenase in non-small cell lung cancer patients treated with 5-FU-based chemotherapy. Int J Oncol 17: 47-54

Huang C, Liu D, Masuya D, Nakashima T, Kameyama K, Ishikawa S, Ueno M, Haba R, Yokomise H (2005) Clinical application of biological markers for treatments of respectable non-small-cell lung cancers. Br J Cancer 92 $1231-1239$

Ichikawa W, Uetake H, Shirota Y, Yamada H, Takahashi T, Nihei Z, Sugihara K, Sasaki Y, Hirayama R (2003a) Both gene expression for orotate phosphoribosyltransferase and its ratio to dihydropyrimidine dehydrogenase influence outcome following fluoropyrimidine-based chemotherapy for metastatic colorectal cancer. $\mathrm{Br} J$ Cancer 89: 1486 1492

Ichikawa W, Uetake H, Shirota Y, Yamada H, Nishi N, Nihei Z, Sugihara K, Hirayama R (2003b) Combination of dihydropyrimidine dehydrogenase and thymidylate synthase gene expressions in primary tumors as predictive parameters for the efficacy of fluoropyrimidine-based chemotherapy for metastatic colorectal cancer. Clin Cancer Res 9: $786-791$

Ichinose Y, Yoshimori K, Sakai H, Nakai Y, Sugiura T, Kawahara M, Niitani H (2004) S-1 plus cisplatin combination chemotherapy in patients with advanced non-small cell lung cancer: a multi-institutional phase II trial. Clin Cancer Res 10: $7860-7864$

Ikeguchi M, Makino M, Kaibara N (2002) Thymidine phosphorylase and dihydropyrimidine dehydrogenase activity in colorectal carcinoma and patients prognosis. Langenbecks Arch Surg 387: 240-245

Isshi K, Sakuyama T, Gen T, Nakamura Y, Kuroda T, Katuyama T, Maekawa Y (2002) Predicting 5-FU sensitivity using human colorectal cancer specimens: comparison of tumor dihydropyrimidine dehydro- genase and orotate phosphoribosyl transferase activities with in vitro chemosensitivity to 5-FU. Int J Clin Oncol 7: 335-342

Ishikawa Y, Kubota T, Otani Y, Watanabe M, Teramoto T, Kumai K, Kitajima M, Takechi T, Okabe H, Fukushima M (1999) Dihydropyrimidine dehydrogenase activity and messenger RNA level may be related to the antitumor effect of 5 -fluorouracil on human tumor xenografts in nude mice. Clin Cancer Res 5: 883-889

Johnson DH, Fehrenbacher L, Novotny WF, Herbst RS, Nemunaitis JJ, Jablons DM, Langer CJ, DeVore III RF, Gaudreault J, Damico LA, Holmgren E, Kabbinavar F (2004) Randomized phase II trial comparing bevacizumab plus carboplatin and paclitaxel with carboplatin and paclitaxel alone in previously untreated locally advanced or metastatic non-small-cell lung cancer. J Clin Oncol 22: 2184-2191

Johnston PG, Lenz HJ, Leichman CG, Danenberg KD, Allegra CJ, Danenberg PV, Leichman L (1995) Thymidylate synthase gene and protein expression correlate and are associated with response to 5fluorouracil in human colorectal and gastric tumors. Cancer Res 55: $1407-1412$

Kanai F, Kawakami T, Hamada H, Sadata A, Yoshida Y, Tanaka T, Ohashi M, Tateishi K, Shiratori Y, Omata M (1998) Adenovirus-mediated transduction of Escherichia coli uracil phosphoribosyltransferase gene sensitizes cancer cells to low concentrations of 5-fluorouracil. Cancer Res 58: $1946-1951$

Kato H, Ichinose Y, Ohta M, Hata E, Tsubota N, Tada H, Watanabe Y, Wada H, Tsuboi M, Hamajima N, Ohta M, Japan Lung Cancer Research Group on Postsurgical Adjuvant Chemotherapy (2004) A randomized trial of adjuvant chemotherapy with uracil-tegafur for adenocarcinoma of the lung. $N$ Engl J Med 350: 1713-1721

Kornmann M, Link KH, Galuba I, Ott K, Schwabe W, Hausler P, Scholz P, Strater J, Polat S, Leibl B, Kettner E, Schlichting C, Baumann W, Schramm H, Hecker U, Ridwelski K, Vogt JH, Zerbian KU, Schutze F, Kreuser ED, Behnke D, Beger HG (2002) Association of time to recurrence with thymidylate synthase and dihydropyrimidine dehydrogenase mRNA expression in stage II and III colorectal cancer. J Gastrointest Surg 6: $331-337$

Lenz HJ, Leichman CG, Danenberg KD, Danenberg PV, Groshen S, Cohen H, Laine L, Crookes P, Silberman H, Baranda J, Garcia Y, Li J, Leichman L (1996) Thymidylate synthase mRNA level in adenocarcinoma of the stomach: a predictor for primary tumor response and overall survival. J Clin Oncol 14: 176-182

Ludwig C, Stoelben E, Olschewski M, Hasse J (2005) Comparison of morbidity, 30-day mortality, and long-term survival after pneumonectomy and sleeve lobectomy for non-small cell lung carcinoma. Ann Thorac Surg 79: $968-973$

Macdonald JS, Astrow AB (2001) Adjuvant therapy of colon cancer. Semin Oncol 28: $30-40$

Matsuyama R, Togo S, Shimizu D, Momiyama N, Ishikawa T, Ichikawa Y, Endo I, Kunisaki C, Suzuki H, Hayasizaki Y, Shimada H (2006) Predicting 5-fluorouracil chemosensitivity of liver metastases from colorectal cancer using primary tumor specimens: Three-gene expression model predicts clinical response. Int J Cancer 119: 406-413

McCarty Jr KS, Szabo E, Flowers JL, Cox EB, Leight GS, Miller L, Konrath J, Soper JT, Budwit DA, Creasman WT, Seigler HF, McCarty Sr KS (1986) Use of a monoclonal anti-estrogen receptor antibody in the immunohistochemical evaluation of human tumors. Cancer Res 46: 4244s -4248s

Mitsudomi T, Kosaka T, Endoh H, Horio Y, Hida T, Mori S, Hatooka S, Shinoda M, Takahashi T, Yatabe Y (2005) Mutations of the epidermal growth factor receptor gene predict prolonged survival after gefitinib treatment in patients with non-small-cell lung cancer with postoperative recurrence. J Clin Oncol 23: 2513-2520

Mizutani Y, Wada H, Fukushima M, Yoshida O, Nakanishi H, Li YN, Miki T (2004) Prognostic significance of orotate phosphoribosyltransferase activity in bladder carcinoma. Cancer 100: 723-731

Mountain CF (1997) Revisions in the international system for staging lung cancer. Chest 111: 1710-1717

Murakami Y, Kazuno H, Emura T, Tsujimoto H, Suzuki N, Fukushima M (2000) Different mechanisms of acquired resistance to fluorinated pyrimidines in human colorectal cancer cells. Int J Oncol 17: 277-283

Nakagawa T, Tanaka F, Takata T, Matsuoka K, Miyahara R, Otake Y, Yanagihara K, Fukushima M, Wada H (2002) Predictive value of dihydropyrimidine dehydrogenase expression in tumor tissue, regarding the efficacy of postoperatively administered UFT (Tegafur+Uracil) in patients with p-stage I nonsmall-cell lung cancer. J Surg Oncol 81: 87-92

Nakagawa T, Otake Y, Yanagihara K, Miyahara R, Ishikawa S, Fukushima M, Wada H, Tanaka F (2004) Expression of thymidylate synthase is 
correlated with proliferative activity in non-small cell lung cancer (NSCLC). Lung Cancer 43: 145-149

Navalgund LG, Rossana C, Muench, AJ, Johnson LF (1980) Cell cycle regulation of thymidylate synthetase gene expression in cultured mouse fibroblasts. J Biol Chem 255: 7386-7390

Ochiai T, Nishimura K, Noguchi H, Kitajima M, Tsukada A, Watanabe E, Nagaoka I, Futagawa S (2006) Prognostic impact of orotate phosphoribosyl transferase among 5-fuorouracil metabolic enzymes in resectable colorectal cancers treated by oral 5 -fluorouracil-based adjuvant chemotherapy. Int J Cancer 118: 3084-3088

Peters GJ, Laurensse E, Leyva A, Lankelma J, Pinedo HM (1986) Sensitivity of human, murine, and rat cells to 5-fluorouracil and 5'-deoxy-5fluorouridine in relation to drug-metabolizing enzymes. Cancer Res 46: $20-28$

Peters GJ, van Groeningen CJ, Laurensse EJ, Pinedo HM (1991) A comparison of 5-fluorouracil metabolism in human colorectal cancer and colon mucosa. Cancer 68: 1903-1909

Rahman L, Voeller D, Rahman M, Lipkowitz S, Allegra C, Barrett JC, Kaye FJ, Zajac-Kaye M (2004) Thymidylate synthase as an oncogene: a novel role for an essential DNA synthesis enzyme. Cancer Cell 5: 341-351

Rocco PM, Antkowiak JG, Takita H, Urschel JD (1996) Long-term outcome after pneumonectomy for nonsmall cell lung cancer. J Surg Oncol 61: $278-280$

Rosell R, Taron M, Alberola V, Massuti B, Felip E (2003) Genetic testing for chemotherapy in non-small cell lung cancer. Lung Cancer 41: S97-S102
Rustum YM, Harstrick A, Cao S, Vanhoefer U, Yin MB, Wilke H, Seeber S (1997) Thymidylate synthase inhibitors in cancer therapy: direct and indirect inhibitors. J Clin Oncol 15: 389-400

Sakamoto K, Sugimoto Y, Miyadera K, Oka T, Fukushima M (2005) Preparation of anti-orotate phosphoribosyltransferase antibody and its application to immunochemical detection in human tumor cells. Int $J$ Mol Med 16: $245-249$

Shirasaka T, Shimamoto Y, Fukushima M (1993) Inhibition by oxonic acid of gastrointestinal toxicity of 5-fluorouracil without loss of its antitumor activity in rats. Cancer Res 53: 4004-4009

Takiuchi H, Ajani JA (1998) Uracil-tegafur in gastric carcinoma: a comprehensive review. J Clin Oncol 16: 2877-2885

Vokes EE, Choy H (2003) Targeted therapies for stage III non-small cell lung cancer: integration in the combined modality setting. Lung Cancer 41: $S 115-S 121$

Wada H, Hitomi S, Teramatsu T (1996) Adjuvant chemotherapy after complete resection in non-small-cell lung cancer. West Japan Study Group for Lung Cancer Surgery. J Clin Oncol 14: 1048-1054

Wei X, McLeod HL, McMurrough J, Gonzalez FJ, Fernandez-Salguero P (1996) Molecular basis of the human dihydropyrimidine dehydrogenase deficiency and 5-fluorouracil toxicity. J Clin Invest 98: 610-615

Yeh KH, Shun CT, Chen CL, Lin JT, Lee WJ, Lee PH, Chen YC, Cheng AL (1998) High expression of thymidylate synthase is associated with the drug resistance of gastric carcinoma to high dose 5-fluorouracil-based systemic chemotherapy. Cancer 82: 1626-163 